\title{
Celetukan Beracun: Pendiskreditan Dokter pada Second Opinion
}

\author{
Muhammad Yadi Permana ${ }^{\mathrm{I}, 2}$, Fadlika Harinda, Azharul Yusri ${ }^{\mathrm{I}}$, Anna Rozaliyani ${ }^{\mathrm{I}, 3}$ \\ ${ }^{1}$ Majelis Kehormatan Etik Kedokteran Pengurus Besar Ikatan Dokter Indonesia \\ ${ }^{2}$ Kelompok Staf Medis (KSM) Bedah RSUP Fatmawati \\ ${ }^{3}$ Departemen Parasitologi, Fakultas Kedokteran Universitas Indonesia
}

\author{
Kata Kunci \\ Etik, informasi, kesejawatan, pindah \\ dokter, rujukan \\ Korespondensi \\ annarozaııı@gmail.com \\ Publikasi \\ (C) 2019 JEKI/ilmiah.id \\ DOI \\ I0.26880/jeki.v3i2.35 \\ Tanggal masuk: Io Agustus 2019 \\ Tanggal ditelaah: I2 Oktober 2019 \\ Tanggal diterima: 17 November 2019 \\ Tanggal publikasi: 30 Desember 2019
}

\begin{abstract}
Abstrak Tidak jarang pasien berpindah dokter dalam upaya mendapat informasi medis mengenai penyakit yang dideritanya. Informasi yang disampaikan secara kurang tepat oleh dokter lainnya dapat menimbulkan ketidakpercayaan pasien terhadap dokter yang dikunjungi sebelumnya. Di sisi lain, praktik kedokteran bersifat kompleks dan dalam menghadapi kasus berbagai pendekatan dapat dilakukan. Perbedaan antar literatur juga memperkaya khasanah pendekatan klinis. Dalam menghadapi kasus seperti ini, nilai kesejawatan harus dijunjung. Seorang dokter harus menjaga martabat dan keluhuran profesi dengan mengedepankan nilai kesejawatan. Apabila dokter merasa janggal terhadap pendekatan medis yang dilakukan oleh teman sejawatnya, tidak boleh langsung mengutarakan kepada pasien yang awam dan berisiko tinggi untuk salah menginterpretasi informasi tersebut. Dokter perlu berkomunikasi pribadi dengan teman sejawat yang bersangkutan untuk mengingatkan teman sejawatnya bila hal yang dilakukan berpotensi menimbulkan kerugian. Majelis Kehormatan Etik Kedokteran (MKEK) dapat berperan sebagai mediator dalam melakukan pembinaan profesi agar tidak terjadi pelanggaran etik terkait dengan perilaku kesejawatan.
\end{abstract}

\begin{abstract}
It is not uncommon for patients to change doctors in effort to obtain medical information about their illness. Information delivered incorrectly by previously visited doctors can lead to mistrust of the patient towards them. On the other hand, the practice of medicine is complex; various approaches can be made in dealing with single case. Differences between literatures also enrich the repertoire of clinical approaches. In dealing with such cases, we have to uphold the value of colleagues. A doctor must maintain the dignity and nobleness of his profession by promoting the value of colleagueship. If a doctor thinks that the medical approach taken by his colleague is inaccurate, it should not be directly told to patients who are lay and at high risk for misinterpreting the information. The doctor needs to communicate privately with the colleague concerned to remind his colleagues if his medical advices has the potential to cause harm. The Medical Ethics Council of Honor (MKEK) can play a role as mediator to avoid ethical violations related to peer behavior.
\end{abstract}

Dalam prinsip etika kedokteran, dikenal asas otonomi, yaitu adanya kebebasan bagi pasien untuk menentukan pelayanan yang dihendaki oleh pasien. Salah satu contoh dari asas tersebut adalah kebebasan bagi pasien untuk memperoleh informasi medis mengenai penyakit yang dideritanya. Hal ini dapat diperoleh dari pencarian melalui mesin pencari, seperti google. Selain itu, pasien juga dapat mendatangi dokter lain untuk mendapatkan informasi medis dari dokter tersebut. Sayangnya, informasi antara satu dokter dengan dokter lainnya bila disampaikan secara kurang tepat berdampak menjatuhkan sehingga timbul rasa ketidakpercayaan dari pasien terhadap salah satu dokter. Hal ini dapat berujung fatal di mana dokter berisiko untuk menghadapi tuntutan hukum bahkan disertai dengan tindak terorisme atau kekerasan oleh 
masyarakat. Lantas di mana peran kesejawatan antar profesi dokter bila dihadapkan dengan situasi demikian?

Awal tahun 2017, dibuka dengan berita terjadinya anarkisme oleh masyarakat terhadap sebuah klinik. Dikabarkan tindakan tersebut terjadi karena adanya kekecewaan dari masyarakat setempat terhadap pelayanan kesehatan yang dianggap menyebabkan terjadinya kematian balita. Menurut MKEK wilayah domisili klinik tersebut, kekecewaan masyarakat berawal dari adanya 'celetukan' dari dokter fasilitas pelayanan kesehatan lain yang memberikan pernyataan bahwa dosis obat yang diberikan oleh dokter di klinik tersebut melebihi takaran yang seharusnya.

Adanya informasi yang didapat dari pihak lain kemudian menjadi bumerang di mana masyarakat secara serta merta beranggapan telah terjadi malapraktik di klinik tersebut. Kekecewaan masyarakat kemudian berujung pada amarah tak tertahankan hingga menimbulkan kekerasan yang berakibat hancurnya bangunan klinik.

\section{Hak pasien dalam pelayanan kesehatan}

Dalam hubungan dokter dan pasien, pasien memiliki hak untuk memilih layanan kesehatan. Hal ini sesuai dengan Undang Undang no. 44 Tahun 2009 tentang Rumah Sakit, bagian empat pasal 32 poin $\mathrm{H}$ tentang hak pasien menyebutkan: „Setiap pasien memiliki hak meminta konsultasi tentang penyakit yang dideritanya kepada dokter lain yang mempunyai Surat Izin Praktik (SIP) baik di dalam maupun di luar Rumah Sakit."

Dalam Kode Etik Kedokteran Indonesia (KODEKI) Tahun 2012 pasal 9 dan 10, disebutkan bahwa seorang dokter wajib bersikap jujur terhadap pasien dan sejawatnya. Seorang dokter wajib mengingatkan sejawatnya pada saat menangani pasien bila dia mengetahui sejawat tersebut memiliki kekurangan dalam karakter/kompetensi, atau melakukan tindak penipuan/penggelapan. Seorang dokter juga wajib menghormati hak-hak pasien, teman sejawatnya, dan tenaga kesehatan lainnya. Selain itu dokter wajib menjaga kepercayaan pasien terhadap profesi. ${ }^{1}$
Berdasarkan Undang-Undang dan Pasal Kode Etik Kedokteran Indonesia ,pasien memiliki hak untuk mendapatkan konsultasi medis dari dokter lain mengenai penyakit yang dideritanya. Seringkali terdapat perbedaan pendapat antara dokter satu dengan dokter yang lainnya, yang terkadang dapat menimbulkan berbagai persepsi pada pasien. Oleh karena itu perlu dibuat Tinjauan Etik Kesejawatan Dokter untuk menjaga kehormatan sejawat dan kepercayaan pasien terhadap profesi sesuai dengan yang telah disebutkan dalam Kode Etik Kedokteran Indonesia.

\section{Tinjauan etik kesejawatan dokter}

Praktik kedokteran merupakan sesuatu yang kompleks dan tidak ada seorang pun yang kompeten atau mampu melayani semua aspek kepentingan medis dan kesejahteraan pasien sendirian. Adanya kerjasama multidisiplin sangat penting dan diperlukan baik dalam pengiriman/perujukan maupun koordinasi perawatan. Koordinasi perawatan yang baik dan integrasi antara tim medis mampu mengurangi risiko malapraktik medis. ${ }^{2}$ Kewajiban saling menjaga harkat dan martabat kedokteran menimbulkan kekokohan korsa profesi. $^{3}$ Seorang dokter seyogyanya tidak memberikan komentar secara tidak bijak atau berkomentar negatif atas terapi yang diberikan teman sejawatnya, tanpa mengetahui dasar kebijakan atau metodologi yang sesungguhnya. ${ }^{1}$

Seorang dokter wajib mengingatkan teman sejawatnya agar yang bersangkutan tidak terjebak dalam kekeliruan medik (medical error) yang secara sadar atau tidak sadar akan berpotensi menimbulkan kerugian bagi pasien, menurunkan martabat profesi, hingga menimbulkan pelanggaran hukum yang dapat menyebabkan kehinaan profesi. ${ }^{4}$ Akan tetapi, untuk menjaga akuntabilitas sejawat di mata sejawat lain sebagai sesama pemberi pelayanan maupun di mata pasien, dalam mengingatkan teman sejawat seorang dokter wajib untuk tidak melakukannya di depan pasien sejawat tersebut.

Organisasi profesi kedokteran memiliki etika sosial/kesejawatan yang unik. Konteks kesejawatan dalam hal ini adalah kesetaraan hubungan antar sejawat. Sesama dokter sebagai 
sejawat memiliki golden rule di mana seorang dokter memperlakukan teman sejawatnya sebagaimana ia ingin diperlakukan. Setiap dokter harus mampu menahan diri untuk tidak membuat sulit, bingung, kecewa/marah sejawatnya sehingga terwujud organisasi profesi yang tangguh.

Salah satu upaya yang dapat dilakukan adalah menghindari perbuatan 'nonkolegial' seperti mengejek teman sejawat dan mempergunjingkan dengan pasien atau orang lain tentang perbuatannya yang dianggap kurang benar. Selain itu seorang dokter harus menghindarkan diri dari mencemarkan nama baik teman sejawat karena hal tersebut secara tidak langsung dapat mencemarkan nama baik sendiri, ibarat seperti peribahasa "menepuk air di dulang terpercik muka sendiri" dengan adanya keterlibatan aspek hukum di dalamnya.

Seorang dokter harus memahami bahwa pada umumnya masyarakat belum begitu memahami tentang hubungan yang begitu erat antara dokter dengan dokter, sehingga mereka kadang-kadang melakukan sesuatu yang cenderung mengadu domba di mana seorang pasien mengunjungi dua atau tiga dokter untuk meminta pendapat terkait penyakitnya dan pada akhirnya memilih dokter yang dalam ucapan dan perbuatannya sesuai dengan selera dan harapannya. Pada kasus lainnya sering kali juga disertai oleh timbulnya tuntutan terhadap dokter lainnya.

Seorang dokter juga jangan sampai mengomentari sejawatnya yang lain melalui media termasuk media sosial. ${ }^{5}$

\section{KESIMPULAN}

Dalam bentuk apapun seorang dokter tidak diperbolehkan merendahkan sesama sejawatnya di hadapan pasien. Ketentuan ini berlaku bukan hanya pada waktu terjadi 'kunjungan second opinion', melainkan pada setiap kondisi lainnya pula. Bila seorang dokter merasa perlu memberikan pengobatan dengan strategi pengobatan yang berbeda dengan teman sejawat lain, ia tidak diperbolehkan untuk mengatakan bahwa pengobatan yang diterima pasien sebelumnya adalah pengobatan dengan kualitas yang buruk. Dokter cukup mengatakan bahwa ia akan memberikan pengobatan dengan cara yang berbeda karena pendekatan yang dilakukan berbeda dari sebelumnya dengan harapan pengobatan yang baru mampu memberikan respons yang lebih baik untuk pasien yang bersangkutan.

Perlu dipertimbangkan agar MKEK dapat berperan sebagai mediator dalam melakukan pembinaan profesi agar tidak terjadi pelanggaran etik berulang-ulang terkait dengan perilaku kesejawatan di Indonesia. Adapun dalam penanganan kasus sulit, sebaiknya dibentuk tim dokter multidisiplin sehingga pasien mendapatkan pelayanan terbaik dan risiko timbulnya 'celetukan beracun' dapat diminimalisasi.

\section{KONFLIK KEPENTINGAN}

Tidak ada konflik kepentingan pada penulis yang terlibat dalam artikel ini.

\section{REFERENSI}

1. Kode etik kedokteran Indonesia tahun 2012. Jakarta: 2012

2. Rodriguez HP, Rodday AMC, Marshall RE, et al. Relation of patients' experience with individual physicians risk to malpractice risk. Int J for Qual Health Care 2008; 20(1):5-12. https://doi.org/10.1093/intqhc/mzm065

3. Thirumoorthy $\mathrm{T}$. The professional role of the doctor as a colleague. SMA news. SMA; Singapore: 2012.

4. Bryden P, Ginsburg S, et al. Professing Professionalism: Are we our own worst enemy? Faculty member's experiences of teaching and evaluating professionalism in medical education at one school. Acad Med 2010; 85:1025-34. https://doi.org/10.1097/ ACM.0b013e3181ce64ae

5. Prawiroharjo P, Libritany N. Tinjauan etika penggunaan media sosial oleh dokter. JEKI. 2017;1(1):31-4. https://doi.org/10.26880/ jeki.v1i1.7. 